\title{
Laboratory and clinical comparison of preservation media and transport conditions for survival of Actinobacillus actinomycetemcomitans
}

\author{
R. PICCOLOMINI, G. CATAMO, G. DI BONAVENTURA, C. PICCIANI \\ and MICHELE PAOLANTONIO*
}

Department of Biomedical Sciences, Clinical Microbiology Laboratory and *School of Dentistry; 'G. D'Annunzio' University, Via dei Vestini, 31 1-66100-Chieti, Italy

\begin{abstract}
The capacity of clinical isolates and type strains of Actinobacillus actinomycetemcomitans to survive in a new transport medium ( $A a T \mathrm{TM}$ ), phosphate-buffered saline (PBS) and Ringer's solution (RS) was evaluated. The effects of exposure to air, transportation time and temperature on viability were also studied. In addition, the culture of $A$. actinomycetemcomitans from subgingival plaque of patients with different forms of periodontitis was quantified. The results following storage in $A a T M, P B S$ and RS showed that $A$. actinomycetemcomitans survived better in AaTM than in PBS or RS when transportation times exceeded $20-22 \mathrm{~h}$, and that survival was enhanced by storage at below $12^{\circ} \mathrm{C}$. Serotype $\mathrm{b}$ strains of $A$. actinomycetemcomitans were able to survive better than either serotype a or $c$. In the clinical study the optimal transportation conditions for subgingival plaque containing $A$. actinomycetemcomitans were $A a \mathrm{TM}$ at a temperature of $8^{\circ} \mathrm{C}$ for $24 \mathrm{~h}$ under anaerobic conditions. These conditions resulted in a high survival and isolation rate for $A$. actinomycetemcomitans without inhibition of the other periodontopathic bacteria isolated from deep periodontal pockets. These findings have practical implications for future multicentre clinical trials in which the transportation of oral specimens over relatively long distances and at different ambient temperatures during various periods of the year are required.
\end{abstract}

\section{Introduction}

Actinobacillus actinomycetemcomitans has been strongly implicated in the pathogenesis of juvenile and adult periodontitis as well as endocarditis [1]. Therefore, microbiological monitoring of patients with periodontal diseases has been employed in diagnosis, choice of therapy, treatment control and risk assessment $[2,3]$. Even if other methods, such as molecular diagnosis, are available as an alternative procedure in periodontal infections, the culture of $A$. actinomycetemcomitans is the only diagnostic method that allows assessment of the susceptibility of this organism to antimicrobial agents.

For maximal recovery of $A$. actinomycetemcomitans from clinical specimens, it is desirable to culture subgingival samples without delay. As this is not always possible because of the distance between non-

Received 31 July 1997; revised version accepted 16 Dec. 1997.

Corresponding author: Dr R. Piccolomini. institutional dental centres and clinical microbiology laboratories, a few studies have evaluated the various conditions required to transport oral plaque over relatively long periods of time. The importance of certain factors, such as metabolic requirements, $\mathrm{pH}$, salt concentration and the effects of freeze-thawing on the growth and viability of $A$. actinomycetemcomitans has been reported [4]. It has also been observed that a delay of 1-2 days in the transportation of plaque samples in Ringer's solution from non-institutional dental centres yielded poor rates of isolation of $A$. actinomycetemcomitans. Furthermore, the survival of A. actinomycetemcomitans was influenced by the duration of exposure to air before culture [5].

Currently, various transport media are available for the preservation of oral samples containing A. actinomycetemcomitans and other periodontopathic bacteria under micro-aerophilic conditions [6-8], but none is ideal, mainly because of their inability to stabilise bacterial cells in the samples without allowing them to proliferate. The conditions required for the transportation of oral specimens before culture influence a 
crucial phase in the microbiological assessment of periodontal infections. Consequently, it is essential to employ a transport medium that can maintain the complex subgingival flora both qualitatively and quantitatively.

The new medium was designed to improve the anaerobic transport of subgingival plaque microorganisms, especially important periodontal pathogens such as $A$. actinomycetemcomitans, and was compared with phosphate-buffered saline (PBS) and Ringer's solution (RS) under various experimental conditions. Subsequently, the recovery of $A$. actinomycetemcomitans and other oral micro-organisms from the subgingival plaque of patients with periodontal diseases following transportation in these three media was compared.

\section{Materials and methods}

\section{Laboratory study}

Micro-organisms. Three type cultures of A. actinomycetemcomitans (ATCC 29522, ATCC 29523 and NCTC 9710) obtained from the American Type Culture Collection (Rockville, MD, USA) and from the National Collection of Type Cultures (London) and 10 wild strains were tested. The latter were randomly chosen fresh strains isolated from periodontal pockets of patients with localised juvenile periodontitis who were being treated in the School of Dentistry at the ' $G$. D'Annunzio' University. Clinical isolates were designated $A$. actinomycetemcomitans if they possessed the following characteristics: gram-negative, facultatively anaerobic short rods; NAD, haemin, oxidase, urease and tryptophanase negative, catalase positive and produced acid from glucose but not from lactose or sucrose $[9,10]$. In addition, the small, convex, adherent colonies on TSBV-agar plates [11] exhibited typical morphology when examined in oblique or transmitted illumination with $\times 10-80$ magnification in a Leica zoom stereomicroscope.

The serotype of $A$. actinomycetemcomitans isolates was confirmed by serology [12]. The methods for raising antisera against $A$. actinomycetemcomitans strain ATCC 29523 (serotype a), strain ATCC 29252 (serotype b) and strain NCTC 9710 (serotype c) were those described by Asikainen et al. [13]. Bacterial cells were grown in $5 \mathrm{ml}$ of Todd-Hewitt Broth (Oxoid, Garbagnate Milanese, Milan, Italy) supplemented with yeast extract $1.2 \% \mathrm{w} / \mathrm{v}$ at $36^{\circ} \mathrm{C}$ for 3 days in an atmosphere containing $\mathrm{CO}_{2} 5 \%$ in air. Antigenic extracts were prepared by autoclaving the $A$. actinomycetemcomitans cells at $121^{\circ} \mathrm{C}$ for $15 \mathrm{~min}$ [14] Immunodiffusion was performed in Noble $1.2 \%$ agar by the Ouchterlony double-diffusion method [15].

For long-term storage, subcultures originating from one colony were frozen in Trypticase Soy Broth
(Oxoid) supplemented with yeast extract (Oxoid) 0.5\% $\mathrm{w} / \mathrm{v}$ and $\mathrm{NaHCO}_{3} \quad 0.05 \% \mathrm{w} / \mathrm{v}$ containing dimethylsulphoxide $10 \%$.

Transport media. A. actinomycetemcomitans transport medium ( $A a \mathrm{TM}$ ) was composed of bacteriological gelatin (LP 008B; Oxoid) $80 \mathrm{~g} / \mathrm{L}$, and re-distilled water $500 \mathrm{ml}$, to which were added the following compounds, obtained from Sigma-Aldrich (Milan, Italy): thioglycollic acid-sodium salt $1.5 \mathrm{~g} / \mathrm{L}$, sodium phosphate $1.1 \mathrm{~g} / \mathrm{L}, \mathrm{NaCl} 5.1 \mathrm{~g} / \mathrm{L}, \mathrm{KCl} 0.30 \mathrm{~g} / \mathrm{L}$, calcium chloride dihydrate $0.15 \mathrm{~g} / \mathrm{L}$, methylene blue $3 \mathrm{mg} / \mathrm{L}$ and redistilled water $490 \mathrm{ml}$. This mixture was boiled on a hotplate while bubbling oxygen-free $\mathrm{CO}_{2}$ gas into the molten transport medium through a Pasteur pipette, for about $4 \mathrm{~min}$, which was then replaced by oxygen-free $\mathrm{N}_{2}$ for a further $2 \mathrm{~min}$. When the methylene blue indicator had become colourless, L-cysteine $(12 \mathrm{mg}$ ) was added, and dissolved by gentle heating in $10 \mathrm{ml}$ of distilled water. Finally, the $\mathrm{pH}$ of the medium was adjusted to 7.5 with boiled then cooled $0.1 \mathrm{~N}$ $\mathrm{NaOH}: 0.1 \mathrm{~N} \mathrm{KOH}(1: 1)$. The medium was transferred immediately to an anaerobic chamber (Don Whitley Scientific; International PBI SpA, Milan, Italy) and dispensed into sterile pre-reduced 8-ml vials. After tight capping, the vials were autoclaved at $115^{\circ} \mathrm{C}$ for $20 \mathrm{~min}$. Vials with an azure or blue colouration were discarded.

PBS was prepared as described by Dulbecco and Vogt in Sambrook et al. [16] and Ringer's solution (RS; Oxoid) was prepared according to the manufacturer's instructions. PBS ( $\mathrm{pH} 7.3)$ and $\mathrm{RS}(\mathrm{pH} 7.0)$ were dispersed in 8-ml screw-capped vials and oxygen-free $\mathrm{N}_{2}$ and $\mathrm{CO}_{2}$ gas was added to the space between the medium surface and the vial top as described above for $A a \mathrm{TM}$. All vials were used within 2 weeks of preparation.

Exposure to air. Fresh strains of A. actinomycetemcomitans were cultivated in anaerobic jars $\left(95 \% \mathrm{~N}_{2}, 5 \%\right.$ $\mathrm{CO}_{2}$ ) for $72-96 \mathrm{~h}$ on TSBV agar at $37^{\circ} \mathrm{C}$ and harvested from plates by scraping, then suspended in $0.1 \mathrm{M}$ phosphate buffer ( $\mathrm{pH}$ 6.8) to a density of $c$. $10^{8}$ cells $/ \mathrm{ml}$, corresponding to a McFarland opacity standard of 0.5 [17]. The time required for the preparation of the bacterial suspensions was no longer than $3 \mathrm{~min}$. To evaluate the effect of exposure to air on survival, $30-\mathrm{ml}$ samples from the suspension were dispensed in opened tissue-culture roller bottles (International PBI) then exposed to air and agitated in a roller culture apparatus (W. Pabisch SpA, Milan, Italy) at room temperature $\left(18^{\circ} \mathrm{C} \pm 1^{\circ} \mathrm{C}\right)$ in a sterile laminar flow cabinet (Gruppo Flow SpA, Opera-Milan, Italy) for 15,30 and $60 \mathrm{~min}$. After each period of air exposure, $100 \mu \mathrm{l}$ were removed to measure survival rate, and following 10-fold serial dilutions in $0.1 \mathrm{M}$ phosphate buffer, samples were inoculated on to three TSBV-agar plates which were incubated in anaerobic jars $\left(95 \% \mathrm{~N}_{2}, 5 \% \mathrm{CO}_{2}\right)$ at $37^{\circ} \mathrm{C}$ for 5 days. Culture 
plates were selected with c. 300 colonies/plate, and after counting the numbers present were then expressed as $\mathrm{cfu} / \mathrm{ml}$.

Holding time and temperature. A. actinomycetemcomitans strains were cultivated as described above for 72 $96 \mathrm{~h}$ on TSBV agar at $37^{\circ} \mathrm{C}$ then suspended in $0.1 \mathrm{M}$ phosphate buffer ( $\mathrm{pH} \mathrm{6.8)} \mathrm{to} \mathrm{a} \mathrm{density} \mathrm{corresponding} \mathrm{to}$ c. $10^{8}$ cells $/ \mathrm{ml}$. A standard inoculum $(100 \mu \mathrm{l})$ of the suspensions prepared for each of the 13 test strains was immediately absorbed on to 12 fine paper points (Dentsply DeTrey, Rome, Italy) which were transferred to four vials of each medium: (i) $A a \mathrm{TM}$, (ii) PBS or (iii) RS. Vials were stored for various periods of time $(8,16$ and $24 \mathrm{~h})$ and at different temperatures $(5,12,20$ and $28^{\circ} \mathrm{C}$ ) before subsequent culture and recovery. All Aa TM vials were incubated at $28^{\circ} \mathrm{C}$ for $20 \mathrm{~min}$ before the contents were mixed in a vortex mixer for $30 \mathrm{~s}$. Samples $(100 \mu \mathrm{l})$ from the undiluted transport medium and from a 100 -fold dilution in $0.1 \mathrm{M}$ phosphate buffer were spread on TSBV-agar for incubation and subsequent estimates of viability.

\section{Clinical study}

Patients and bacteriological procedures. Seventy patients with different forms of early-onset and adult periodontitis were included in this part of the study. None of the subjects had a history of serious illness nor had they received antibiotics for at least 4 months before the microbiological investigation. The most diseased site (pocket depth of $\geqslant 6 \mathrm{~mm}$ ) in each quadrant was selected for bacteriological sampling, which was performed immediately after recording plaque indices and before the assessment of the gingival bleeding index [18]. After removal of supragingival plaque by a scaler, the gingival surface was dried by a gentle flow of sterile, oxygen-free $\mathrm{CO}_{2}$ gas. Plaque samples were collected by the insertion of three sterile fine paper points into the periodontal pocket. These were left in situ for $15 \mathrm{~s}$ then removed at the same time; each was immediately transferred into a vial containing $1.0 \mathrm{ml}$ of one of the three test transport media. The paper points from each quadrant were added to the same vial to produce a pooled 'mouth' sample for each patient. Plaque samples were maintained at a temperature of $+8^{\circ} \mathrm{C}\left( \pm 1^{\circ} \mathrm{C}\right)$ in a portable refrigerator (Penguin TR825H; PBI International, Milan, Italy) and transported to the Clinical Microbiology Laboratory of the 'G. D'Annunzio' University of Chieti where they were processed $24 \mathrm{~h}$ after collection.

Samples in the $A a \mathrm{TM}$ vials were warmed to $28^{\circ} \mathrm{C}$ for $20 \mathrm{~min}$ before processing. All samples were mixed for $30 \mathrm{~s}$ in a vortex mixer at the maximal setting then diluted 1 in 10 in $0.1 \mathrm{M}$ phosphate buffer. Samples $(100 \mu 1)$ of the appropriate dilution of each pooled plaque sample were inoculated in triplicate on to freshly prepared TSBV-agar plates, Columbia Blood
Agar Base (CBA; Oxoid) enriched with non-sporeforming anaerobic bacteria supplement (SR 107B + Tween 80; Oxoid) and Wilkins-Chalgren Anaerobe Blood Agar (WCAB; Oxoid) enriched with gram-negative anaerobic bacteria supplement (SR 108B; Oxoid) for total anaerobic colony counts. The plates were then cultured at $37^{\circ} \mathrm{C}$ in a $\mathrm{CO}_{2} 5 \%$ incubator (TSBV), aerobically (CBA), and in an anaerobic chamber (WCAB) for 5 days, then examined for the presence and enumeration of $A$. actinomycetemcomitans and the presumptive identification of aerobic and anaerobic micro-organisms from plaque. Plates containing 30-300 cfu were selected for quantitative estimation of bacterial growth.

A. actinomycetemcomitans on TSBV-agar was identified by the criteria described previously. Initial differentiation of the black-pigmented Porphyromonas and Prevotella spp. was based on cell and colony morphology, pigment production, fluorescence under long-wave UV light [19], and susceptibility or resistance to special-potency antibiotic disks (vancomycin $5 \mu \mathrm{g}$; kanamycin $1000 \mu \mathrm{g}$; colistin $10 \mu \mathrm{g}$; Oxoid) [20]. Colonies of gram-negative filamentous, spindle-shaped and non-motile rods were presumptively classified as Fusobacterium spp. and were easily differentiated from Capnocytophaga spp. because of the micro-aerophilic characteristic of the latter. Grampositive Peptostreptococcus spp. were preliminarily identified on the basis of colony morphology on the WCAB plates as small white colonies with haemolysis. A definitive identification of all representative isolates was then obtained by subculturing on to Brucella Blood Agar (Oxoid) followed by inoculation of purified cultures into a commercially packaged automated system (Vitek; bioMérieux Italia SpA, Rome, Italy).

The proportion of $A$. actinomycetemcomitans and the aerobic microflora present in the pooled plaque samples were determined by dividing the number of typical colonies on TSBV-agar and the total cfu on CBA, respectively, by the total anaerobic colony counts on the WCAB plates; the results being reported as a percentage of the total anaerobic count.

\section{Results}

\section{Laboratory study}

Influence of exposure to air. The effect of exposure to air on the viability of $A$. actinomycetemcomitans is presented in Table 1. The type strains tested were more aerotolerant than fresh clinical isolates and after exposure to air for $30 \mathrm{~min}$, both the size and number of colonies recovered was greater than that achieved with any of the 10 clinical isolates (seven showed moderate growth and three scanty growth). When exposure to air was extended to $60 \mathrm{~min}$, the majority of the strains tested $(84.6 \%)$ could not be subsequently 
Table 1. Recovery of three type strains and 10 clinical isolates of $A$. actinomycetemcomitans in $0.1 \mathrm{M}$ phosphate buffer after various holding times with exposure to air at room temperature $\left(18^{\circ} \mathrm{C} \pm 1^{\circ} \mathrm{C}\right)$

\begin{tabular}{lccc}
\hline & \multicolumn{3}{c}{ Recovery after holding for } \\
\cline { 2 - 4 } Strain (serotype) & 15 min & 30 min & 60 min \\
\hline ATCC 29522 (b) & $3+$ & $2+$ & \pm \\
ATCC 29523 (a) & $3+$ & $2+$ & - \\
NCTC 9710 (c) & $3+$ & $2+$ & - \\
UdA 06 (a) & $2+$ & \pm & - \\
UdA 07 (b) & $3+$ & + & - \\
UdA 12 (c) & $3+$ & + & - \\
UdA 14 (a) & $2+$ & \pm & - \\
UdA 15 (b) & $3+$ & + & - \\
UdA 18 (b) & $3+$ & + & - \\
UdA 23 (b) & $3+$ & + & \pm \\
UdA 25 (c) & $2+$ & + & - \\
UdA 37 (b) & $3+$ & + & - \\
UdA 43 (a) & $2+$ & \pm & - \\
\hline
\end{tabular}

An inoculum of $10^{6} \mathrm{cfu} / \mathrm{ml}$ was used and recovery was graded as follows: $3+$, abundant $\left(>10^{5} \mathrm{cfu} / \mathrm{ml}\right) ; 2+$, good $\left(10^{5}-10^{4} \mathrm{cfu} / \mathrm{ml}\right)$; + , moderate $\left(10^{3}-10^{2} \mathrm{cfu} / \mathrm{ml}\right) ; \pm$, scanty $\left(<10^{2} \mathrm{cfu} / \mathrm{ml}\right) ;-$, no growth. recovered and two strains, a type strain and a fresh clinical isolate both belonging to serotype $b$, grew poorly.

Influence of medium composition, holding time and temperature. The recovery of $A$. actinomycetemcomitans from $A a \mathrm{TM}$ was superior to that obtained from other transport media (Table 2). After $8 \mathrm{~h}$ at holding temperatures of 5,12 and $20^{\circ} \mathrm{C}$, all 13 strains were recovered from $A a \mathrm{TM}$, compared with six from PBS and none from RS. The number of clinical strains of $A$. actinomycetemcomitans isolated from $\mathrm{AaTM}$ was $10^{2}-$ $10^{4}$ times greater than the numbers isolated from either PBS or RS after $16 \mathrm{~h}$ at 12 and $20^{\circ} \mathrm{C}$. When the temperature was increased to $28^{\circ} \mathrm{C}$, the majority of $A$. actinomycetemcomitans strains tested failed to grow in either PBS or RS; conversely, the serotype b strains shown moderate growth in $A a$ TM (data not shown). No strain of $A$. actinomycetemcomitans survived incubation in PBS or RS at $20^{\circ} \mathrm{C}$ for $24 \mathrm{~h}$, whereas five of the

Table 2. Recovery of 13 strains of $A$. actinomycetemcomitans from transport medium ( $A a \mathrm{TM})$, PBS and Ringer's solution (RS) after exposure to different temperatures for 8,16 and $24 \mathrm{~h}$

\begin{tabular}{|c|c|c|c|c|c|c|c|c|c|c|}
\hline \multirow[b]{3}{*}{ Strain (serotype) } & \multirow[b]{3}{*}{ Exposure (h) } & \multicolumn{9}{|c|}{ Recovery after holding at } \\
\hline & & \multicolumn{3}{|c|}{$5^{\circ} \mathrm{C}$} & \multicolumn{3}{|c|}{$12^{\circ} \mathrm{C}$} & \multicolumn{3}{|c|}{$20^{\circ} \mathrm{C}$} \\
\hline & & AaTM & PBS & RS & $A a \mathrm{TM}$ & PBS & RS & $A a \mathrm{TM}$ & PBS & RS \\
\hline \multirow[t]{3}{*}{ ATCC 29522 (b) } & 8 & $3+$ & $3+$ & $3+$ & $3+$ & $3+$ & \pm & $3+$ & + & - \\
\hline & 16 & $3+$ & $3+$ & + & $3+$ & $2+$ & \pm & $2+$ & + & - \\
\hline & 24 & $3+$ & + & \pm & $2+$ & + & - & + & \pm & - \\
\hline \multirow[t]{3}{*}{ ATCC 29523 (a) } & 8 & $3+$ & $3+$ & $2+$ & $3+$ & $3+$ & \pm & $2+$ & - & - \\
\hline & 16 & $3+$ & $2+$ & \pm & $3+$ & + & - & + & - & - \\
\hline & 24 & $2+$ & + & - & + & - & - & - & - & - \\
\hline \multirow[t]{3}{*}{ NCTC 9710 (c) } & 8 & $3+$ & $2+$ & + & $3+$ & $2+$ & \pm & $2+$ & - & - \\
\hline & 16 & $2+$ & $2+$ & \pm & $2+$ & + & - & + & - & - \\
\hline & 24 & $2+$ & \pm & - & \pm & - & - & - & - & - \\
\hline \multirow[t]{3}{*}{ UdA 06 (a) } & 8 & $3+$ & $3+$ & $2+$ & $3+$ & $2+$ & \pm & $2+$ & - & - \\
\hline & 16 & $2+$ & $2+$ & \pm & $2+$ & \pm & - & \pm & - & - \\
\hline & 24 & + & \pm & - & \pm & - & - & - & - & - \\
\hline \multirow[t]{3}{*}{ UdA 07 (b) } & 8 & $3+$ & $3+$ & $3+$ & $3+$ & $2+$ & \pm & $3+$ & + & - \\
\hline & 16 & $3+$ & $3+$ & + & $3+$ & + & \pm & $2+$ & \pm & - \\
\hline & 24 & $3+$ & $2+$ & - & + & - & - & \pm & - & - \\
\hline \multirow[t]{3}{*}{$\mathrm{UdA} 12(\mathrm{c})$} & 8 & $3+$ & $2+$ & + & $2+$ & + & - & + & - & - \\
\hline & 16 & $2+$ & $2+$ & - & + & \pm & - & \pm & - & - \\
\hline & 24 & + & \pm & - & \pm & - & - & - & - & - \\
\hline \multirow[t]{3}{*}{ UdA 14 (a) } & 8 & $3+$ & $2+$ & $2+$ & $2+$ & + & - & $2+$ & - & - \\
\hline & 16 & $3+$ & $2+$ & - & $2+$ & \pm & - & + & - & - \\
\hline & 24 & $2+$ & \pm & - & + & - & - & - & - & - \\
\hline \multirow[t]{3}{*}{ UdA 15 (b) } & 8 & $3+$ & $3+$ & $2+$ & $3+$ & $2+$ & + & $3+$ & + & - \\
\hline & 16 & $3+$ & $3+$ & + & $3+$ & + & \pm & + & \pm & - \\
\hline & 24 & $3+$ & $2+$ & \pm & + & \pm & - & - & - & - \\
\hline \multirow[t]{3}{*}{ UdA 18 (b) } & 8 & $3+$ & $3+$ & $2+$ & $3+$ & $2+$ & + & $3+$ & \pm & - \\
\hline & 16 & $3+$ & $3+$ & + & $3+$ & + & \pm & $2+$ & \pm & - \\
\hline & 24 & $3+$ & $2+$ & \pm & $2+$ & \pm & - & + & - & - \\
\hline \multirow[t]{3}{*}{ UdA 23 (b) } & 8 & $3+$ & $3+$ & $3+$ & $3+$ & $2+$ & + & $3+$ & \pm & - \\
\hline & 16 & $3+$ & $3+$ & + & $3+$ & + & \pm & $2+$ & - & - \\
\hline & 24 & $3+$ & + & - & $2+$ & - & - & + & - & - \\
\hline \multirow[t]{3}{*}{ UdA $25(\mathrm{c})$} & 8 & $3+$ & $2+$ & $2+$ & $2+$ & + & - & + & -- & - \\
\hline & 16 & $2+$ & + & - & + & \pm & - & - & - & - \\
\hline & 24 & + & - & - & \pm & - & - & - & - & - \\
\hline \multirow[t]{3}{*}{ UdA 37 (b) } & 8 & $3+$ & $3+$ & $2+$ & $3+$ & $3+$ & + & $3+$ & + & - \\
\hline & 16 & $3+$ & $3+$ & \pm & $3+$ & + & - & + & - & - \\
\hline & 24 & $3+$ & + & - & $2+$ & - & - & + & - & - \\
\hline \multirow[t]{3}{*}{ UdA 43 (a) } & 8 & $3+$ & $2+$ & $2+$ & $2+$ & $2+$ & - & $2+$ & - & - \\
\hline & 16 & $2+$ & + & - & $2+$ & \pm & - & \pm & - & - \\
\hline & 24 & $2+$ & - & - & + & - & - & - & - & - \\
\hline
\end{tabular}

See footnote to Table 1 . 
13 strains were recovered from $A a T M$. A clear correlation between temperature, time and recovery was demonstrated; and providing that the holding period was $<8 \mathrm{~h}$, the re-isolation of all 13 strains from $A a T M$ was possible at temperatures of up to $20^{\circ} \mathrm{C}$. If the holding time was $>8 \mathrm{~h}$, the influence of temperature became critical, as only four of the 10 clinical isolates could be recovered in small numbers after $16 \mathrm{~h}$ at $28^{\circ} \mathrm{C}$. After storage for $24 \mathrm{~h}$, all strains of A. actinomycetemcomitans tested survived when they were held in $\mathrm{AaTM}$ at $12^{\circ} \mathrm{C}$, but only three serotype b strains were recovered from $\mathrm{PBS}$ and none from RS.

\section{Clinical study}

The total viable anaerobic count of plaque samples from deep periodontal pockets on WCAB plates was significantly higher in samples held in $A a$ TM than in PBS or in RS $(\mathrm{p}<0.01$; Wilcoxon rank sum test) (Table 3 ). The mean percentage of A. actinomycetemcomitans of the total viable plaque counts was $10.3 \%$ when samples were stored for $24 \mathrm{~h}$ at $8^{\circ} \mathrm{C}$ in $\mathrm{AaTM}$. This was consistently higher than those exhibited by plaque samples stored under the same conditions in PBS $(2.1 \%, \mathrm{p}<0.05)$ or in $\operatorname{RS}(1.9 \%, \mathrm{p}<0.01)$.

Other potential pathogens ( $F$. nucleatum, $P$. gingivalis, Prev. intermedia and Prev. melaninogenica) were also isolated in significantly higher numbers $(\mathrm{p}<0.05)$ from 70 subgingival plaque samples when stored in AaTM for $24 \mathrm{~h}$ at $8^{\circ} \mathrm{C}$, compared with PBS or RS (data not shown). However, Peptostreptococcus spp., Capnocytophaga spp., Candida albicans and certain coliforms were more frequently isolated from PBS or RS than from $A a T M$.

\section{Discussion}

A. actinomycetemcomitans is a fastidious periodontopathic micro-organism and for optimal isolation from subgingival plaque it is essential to culture the sample as soon as possible. However, delay is usually unavoidable and subgingival plaque is placed temporarily in transport medium. It is likely that a serious limitation to the efficient isolation of A. actinomycetemcomitans from oral specimens is the cumulative effect of inappropriate transport conditions, such as the duration of exposure to air, the delay between sampling and culture, and incorrect transport temperature. This is supported by studies which show that $A$. actinomycetemcomitans is able to survive for up to $20 \mathrm{~min}$ in PBS at $22^{\circ} \mathrm{C}$, but survives better at low temperatures [4]. Pre-reduced anaerobically sterilised Ringer's solution has been employed for transporting subgingival plaque [21], but $<1 \%$ of $A$. actinomycetemcomitans was detected from the total culturable microbiota. It appeared that atmospheric levels of oxygen were toxic for $A$. actinomycetemcomitans, especially in the case of serotypes a and $\mathrm{c}$.

In the present study, oxygen was excluded from all three transport media at different stages, but $\mathrm{AaTM}$ proved to be most effective, which may be due in part to the presence of gelatin $(8 \%)$ in $A a \mathrm{TM}$. This was liquified by heating samples to $28-30^{\circ} \mathrm{C}$ followed by vortex mixing before inoculation. AaTM allows plaque micro-organisms to survive better than either PBS or RS at holding times that exceed $20-22 \mathrm{~h}$, and this survival is enhanced at storage temperatures below $12^{\circ} \mathrm{C}$. These results indicate that the recovery rates of $A$. actinomycetemcomitans were significantly higher when $A a \mathrm{TM}$ was used. All strains of $A$. actinomycetemcomitans stored in AaTM survived for as long as $24 \mathrm{~h}$ at $8^{\circ} \mathrm{C}$, permitting the successful recovery of the micro-organism without inhibition of the other periodontopathic bacteria (such as $P$. gingivalis, Prev. melaninogenica, Prev. intermedia and $F$. nucleatum) isolated from deep periodontal pockets.

Xylose positive serotype $\mathrm{b}$ strains of $A$. actinomycetemcomitans were able to survive in $A a T M$ better than serotypes a and $\mathrm{c}$ in the laboratory study. The reason for this result is unknown, but may be due to the presence of a physicochemical complex present only in serotype $b$ cells that protects against exposure to air, holding time and temperature. This could also explain in part why serotype $\mathrm{b}$ strains of $A$. actinomycetemcomitans have been isolated more commonly from subgingival plaque of patients with localised juvenile periodontitis than either serotype a or c [22].

As only one optimal, but expensive and complex transport medium suitable for mailing of A. actino-

Table 3. Total viable count (anaerobic) and total aerobic count and mean percentage of $A$. actinomycetemcomitans and aerobic microflora of total viable count in 70 subgingival plaque samples held for $24 \mathrm{~h}$ in $A a \mathrm{TM}$, PBS and RS at $8^{\circ} \mathrm{C}$ $\left( \pm 1.0^{\circ} \mathrm{C}\right)$ before culture

\begin{tabular}{|c|c|c|c|c|}
\hline \multirow{2}{*}{$\begin{array}{l}\text { Transport } \\
\text { medium }\end{array}$} & \multicolumn{2}{|c|}{ Mean (range) total count cfu $\times 10^{6}$} & \multicolumn{2}{|c|}{ Mean (range) percent of total anaerobic count } \\
\hline & anaerobic & aerobic & A. actinomycetemcomitans & aerobic flora \\
\hline Aa TM & $\begin{array}{c}18.4 \\
(1.46-96.4)\end{array}$ & $\begin{array}{c}7.6 \\
(0.49-28.6)\end{array}$ & $\begin{array}{c}10.3 \\
(1.6-32.4)\end{array}$ & $\begin{array}{c}41.3 \\
(20.6-79.3)\end{array}$ \\
\hline PBS & $\begin{array}{c}6.2 \\
(0.051-21.2)\end{array}$ & $\frac{1.3}{(0.035-5.6)}$ & $\begin{array}{c}2.1 \\
(0.9-7.6)\end{array}$ & $\begin{array}{c}20.9 \\
(19.3-81.2)\end{array}$ \\
\hline RS & $\begin{array}{c}4.6 \\
(0.057-19.8)\end{array}$ & $\begin{array}{c}0.92 \\
(0.030-6.3)\end{array}$ & $\begin{array}{c}1.9 \\
(0.7-3.8)\end{array}$ & $\begin{array}{c}20 \\
(18.6-80.6)\end{array}$ \\
\hline
\end{tabular}


mycetemcomitans has been developed previously [23], Aa TM might represent an alternative for this purpose, although the need to maintain samples between 8 and $12^{\circ} \mathrm{C}$ and limit the transportation time to $<24 \mathrm{~h}$ makes it less convenient to employ. Also, some species did not survive well in AaTM (Peptostreptococcus spp., Capnocytophaga spp. and Candida spp.). Therefore, a study comparing the medium described by Dahlen et al. [23] and $A a \mathrm{TM}$ is required so that the best medium and transportation conditions for conveying plaque samples over long distances can be identified.

We thank Carmelita Della Pelle, Simonetta D'Ercole and Stefania Lupo for their technical assistance. This work was supported by grants from the Ministero dell'Università e Ricerca Scientifica e Tecnologica (MURST, 'ex-quote 40\% e 60\%').

\section{References}

1. Schack SH, Smith PW, Penn RG, Rapoport JM. Endocarditis caused by Actinobacillus actinomycetemcomitans. $J$ Clin Microbiol 1984; 20: 579-581.

2. Listgarten MA. A rationale for monitoring the periodontal microbiota after periodontal treatment. J Periodontol 1988; 59: 439-444.

3. Maiden MFJ, Carman RJ, Curtis MA et al. Detection of highrisk groups and individuals for periodontal diseases: laboratory markers based on the microbiological analysis of subgingival plaque. J Clin Periodontol 1990; 17: 1-13.

4. Sreenivasan PK, Meyer DH, Fives-Taylor PM. Factors influencing the growth and viability of Actinobacillus actinomycetemcomitans. Oral Microbiol Immunol 1993; 8: 361-369.

5. Paolantonio M, di Girolamo G, Pedrazzoli V et al. Occurrence of Actinobacillus actinomycetemcomitans in patients wearing orthodontic appliances. A cross-sectional study. $J$ Clin Periodontol 1996; 23: 112-118.

6. Helstad AG, Kimball JL, Maki DG. Recovery of anaerobic, facultative, and aerobic bacteria from clinical specimens in three anaerobic transport systems. J Clin Microbiol 1977; 5: $564-569$.

7. Hill GB. Effects of storage in an anaerobic transport system on bacteria in known polymicrobial mixtures and in clinical specimens. J Clin Microbiol 1978; 8: 680-688.

8. Spiegel CA, Minah GE, Krywolap GN. Improved procedure for transport of dental plaque samples and other clinical specimens containing anaerobic bacteria. $J$ Clin Microbiol 1979; 9: $637-639$.

9. Slots J. Salient biochemical characters of Actinobacillus actinomycetemcomitans. Arch Microbiol 1982; 131: 60-67.

10. Slots J. Rapid identification of important periodontal microorganisms by cultivation. Oral Microbiol Immunol 1986; 1: $48-57$.

11. Slots J. Selective medium for isolation of Actinobacillus actinomycetemcomitans. J Clin Microbiol 1982; 15: 606-609.

12. Amano $K$, Nishihara $T$, Shibuya $N$, Noguchi $T$, Koga $T$. Immunochemical and structural characterization of a serotypespecific polysaccharide antigen from Actinobacillus actinomycetemcomitans Y4 (serotype b). Infect Immun 1989; 57: 2942-2946.

13. Asikainen S, Lai C-H, Alaluusua S, Slots J. Distribution of Actinobacillus actinomycetemcomitans serotypes in periodontal health and disease. Oral Microbiol Immunol 1991; 6: 115-118.

14. Rantz LA, Randall E. Use of autoclaved extracts of hemolytic streptococci for serological grouping. Stanford Med Bull 1955; 13: $290-291$.

15. Ouchterlony O. Diffusion-in-gel methods for immunological analysis. II. Progr Allerg 1962; 6: 30-154

16. Sambrook J, Fritsch EF, Maniatis T. Molecular cloning: a laboratory manual, 2nd edn. Cold Spring Harbor, NY, Cold Spring Harbor Laboratory Press. 1989: B.13.

17. Hendrickson DA, Krenz MM. Reagents and stains. In: Balows A, Hausler WJ, Herrmann KL, Isenberg HD, Shadomy HJ (eds) Manual of clinical microbiology, 5th edn. Washington, DC, American Society for Microbiology. 1991: 1289-1314.

18. Ainamo J, Bay I. Problems and proposals for recording gingivitis and plaque. Int Dent $J$ 1975; 25: 229-235.

19. Slots J, Reynolds HS. Long-wave UV-light fluorescence for identification of black-pigmented Bacteroides spp. $J$ Clin Microbiol 1982; 16: 1148-1151.

20. Summanen P. Rapid disk and spot tests for the identification of anaerobes. In: Isenberg HD (ed) Clinical microbiology procedures handbook. Washington, DC, American Society for Microbiology. 1992: 2.5.6-2.5.7.

21. Haffajee AD, Socransky SS, Dzink JL, Taubman MA, Ebersole JL, Smith DJ. Clinical, microbiological and immunological features of subjects with destructive periodontal diseases. $J$ Clin Periodontol 1988; 15: 240-246.

22. Zambon JJ, Umemoto T, De Nardin E, Nakazawa F, Christersson FA, Genco RJ. Actinobacillus actinomycetemcomitans in the pathogenesis of human periodontal disease. $A d v$ Dent Res 1988; 2: 269-274.

23. Dahlen G, Pipattanogovit P, Rosling B, Möller ÅJR. A comparison of two transport media for saliva and subgingival samples. Oral Microbiol Immunol 1993; 8: 375-382. 